BMJ Open

Diabetes

Research

$\&$ Care

\section{Combined therapy of photobiomodulation and adipose- derived stem cells synergistically improve healing in an ischemic, infected and delayed healing wound model in rats with type 1 diabetes mellitus}

To cite:

Ebrahimpour-Malekshah $\mathrm{R}$, Amini A, Zare F, et al. Combined therapy of photobiomodulation and adipose-derived stem cells synergistically improve healing in an ischemic, infected and delayed healing wound model in rats with type 1 diabetes mellitus. BMJ Open Diab Res Care 2020;8:e001033. doi:10.1136/ bmjdrc-2019-001033

- Additional material is published online only. To view, please visit the journal online (http://dx.doi.org/10.1136/ bmjdrc-2019-001033).

Received 12 November 2019 Revised 16 December 2019 Accepted 26 December 2019

Check for updates

C A Author(s) (or their employer(s)) 2020. Re-use permitted under CC BY-NC. No commercial re-use. See rights and permissions. Published by BMJ.

For numbered affiliations see end of article.

Correspondence to Dr Mohammad Bayat; bayat_m@yahoo.com and Dr Abdollah Amini;

dr.amini@sbmu.ac.ir

\section{ABSTRACT}

Objective We assessed the therapeutic effects of photobiomodulation (PBM) and adipose-derived stem cell (ADS) treatments individually and together on the maturation step of repairing of a delayed healing wound model in rats with type 1 diabetes mellitus (DM1).

Research design and methods We randomly assigned 24 rats with DM1 to four groups ( $n=6$ per group). Group 1 was the control (placebo) group. In group 2, allograft human ADSs were transplanted. Group 3 was subjected to PBM (wavelength: $890 \mathrm{~nm}$, peak power output: $80 \mathrm{~W}$, pulse frequency: $80 \mathrm{~Hz}$, pulsed duration: $180 \mathrm{~ns}$, duration of exposure for each point: $200 \mathrm{~s}$, power density: $0.001 \mathrm{~W} / \mathrm{cm}^{2}$, energy density: $0.2 \mathrm{~J} / \mathrm{cm}^{2}$ ) immediately after surgery, which continued for 6 days per week for 16 days. Group 4 received both the human ADS and PBM. In addition, we inflicted an ischemic, delayed healing, and infected wound simulation in all of the rats. The wounds were infected with methicillinresistant Staphylococcus aureus (MRSA).

Results All three treatment regimens significantly decreased the amount of microbial flora, significantly increased wound strength and significantly modulated inflammatory response and significantly increased angiogenesis on day 16. Microbiological analysis showed that PBM+ADS was significantly better than PBM and ADS alone. In terms of wound closure rate and angiogenesis, PBM+ADS was significantly better than the PBM, ADS and control groups. Conclusions Combination therapy of $\mathrm{PBM}+\mathrm{ADS}$ is more effective that either PBM or ADS in stimulating skin injury repair, and modulating inflammatory response in an MRSAinfected wound model of rats with DM1.

\section{INTRODUCTION}

Type 1 diabetes mellitus (DM1) is a chronic illness that results from inadequate insulin

\section{Significance of this study}

What is already known about this subject?

- The positive impact of combined application of photobiomodulation (PBM) and Adipose derived stem cells (ADS) has been reported in some ischemic non diabetic tissue in animal models.

What are the new findings?

- We found that PBM and ADS alone or together significantly hasten the skin injury repair in an ischemic delayed healing and MRSA-infected wound simulation in rats with type one diabetes.

- Furthermore, combined use of PBM and ADS have confirmed a synergistic impact.

How might these results change the focus of research or clinical practice?

$>$ Our results might support new healing attitudes for a cure and resolution of delayed healing of diabetic foot ulcer in patients.

- This approach could modulate the immune system in patients with diabetes who have delayed healing and infected diabetic foot ulcer.

- The combined application of ADS and PBM would be significant for advancing the development of a new treatment for delayed healing and infected diabetic foot ulcers in patients, and it would provide new findings about modulating the inflammatory response in diabetic foot ulcer.

production by the pancreas. ${ }^{1}$ In 2017 , there were 451 million individuals worldwide who suffered from DM. ${ }^{2}$ The incidence of DM1 is estimated to increase to nearly 700 million 
by 2045 . Approximately $50 \%$ of all persons living with DM are unidentified. ${ }^{2}$

People who suffer from DM are at greater risk for diabetic foot ulcers (DFUs). DFUs are the result of concurrent activities of many causative sources. Persistent hyperglycemia, peripheral neuropathy, ischemia from peripheral vasculopathy, immunosuppression and infection are the major pathological elements that lead to foot deformities and DFUs. ${ }^{3}$ Of note, any DFU is assumed to have blood vessel deficiencies, even without direct verification. ${ }^{4}$ In addition to metabolic aberrations, DM causes overproduction of mitochondrial superoxide and reactive oxygen species (ROS) in endothelial cells, which further leads to reduced angiogenesis and ischemia. ${ }^{5}$

Lower limb amputation (LLA) occurs in 5\%-24\% of patients with DFUs within 180-545 days after the initial diagnosis. ${ }^{6}$ Worldwide, DFUs are the most common complications that lead to huge financial problems for the patients, their relatives and the public. ${ }^{7}$ The total clinical cost for managing diabetic lower limb complications in the USA is approximately US $\$ 10.5$ billion in addition to the cost of DM management. ${ }^{8}$

Approximately $50 \%$ of LLA occur in patients with DM, and most are from microbial DFU. ${ }^{9}$ The prevalence of methicillin-resistant Staphylococcus aureus (MRSA) in infected DFU is $15 \%-30 \% .{ }^{10}$ Among microbes $S$. aureus is the most prevalent. Overuse of antibiotics to combat infected diabetic ulcers have led to an explosion of antibiotic resistance with delayed macrophage response, which poses a serious threat to global public health. ${ }^{11}$

DFU is the main medical threat due a lack of knowledge about its pathophysiology. ${ }^{12}$ Weakened wound repair in DM is identified by reduced angiogenesis, decreased endothelial progenitor cell recruitment, reduced fibroblast and keratinocyte proliferation and migration and delayed macrophage response. ${ }^{12} 13$ The capability to quickly repair the wound is demanding and is the crucial aim for a cure for DFU. ${ }^{14}$ Both protective and curative measures consist of the use of bactericidal mediators, wet absorbent and bioengineered gauzes, vacuum-assisted closure, Regranex PDGF gel and unloading to stimulate the repair process. ${ }^{15}$ However, none of these measures show any distinct advantage over the others; the cure of chronic wounds and DFU remains problematic and prolonged. ${ }^{14}{ }^{15}$ Thus, new approaches are urgently needed to combat infection and stimulate tissue repair in diabetic wounds. Concentrated efforts on the effectiveness of prognostic laboratory experiments, technologies for new cures and selective and focused approaches are required. ${ }^{4}$

Mesenchymal stem cells (MSCs) can effectively enhance repair of wound. The ability of MSCs to differentiate into various cell lines and their low immunogenicity make them highly attractive for therapeutic use in DFUs. MSCs stimulate cell migration, new blood vessel formation, re-epithelialization and new wound bed formation and maturation. In addition, they reduce the inflammatory response, enhance wound contraction, and can improve healing. ${ }^{16}$
Adipose-derived stem cells (ADSs) are great replacements of bone marrow (BM) MSCs because they can be simply harvested from adipose tissue and can grow in a culture system. Published investigational probes have indicated that ADSs could improve wound repair via boosting re-epithelialization and new wound bed formation. They modulate the inflammatory reaction, have an anti-apoptotic impact and secrete angiogenic growth factors. ${ }^{17}$

Probes using animal simulation ${ }^{18}$ and studies in humans ${ }^{19}$ have been performed to display the probable favorable impacts of ADS in wounds and ischemic organs in animals and in patients who suffer from DM. Despite the current achievements, several chief obstacles remain before they can be effectively used to benefit diabetic ADS in wound repair. First, the aberrant in vivo micro milieu of people with DM adversely affects the therapeutic biological action of the ADSs on wound repair. ${ }^{20}$ Second, the systemic deficiency of the healing potential of diabetic ADS in vivo. ${ }^{21}$ Third, ADS is physiologically damaged.$^{22}$ Finally, ADSs cannot provide a blood vessel complex. Consequently, these diabetic ADS are weak in stimulating new blood vessel formation and soft tissue repair. $^{23}$

Photobiomodulation (PBM) decreases pain, and inflammation, and enhances injury repair, and prevents cell and tissue damage. ${ }^{24}$ We believe that PBM could overcome these ADS deficiencies and synergize its positive effects in stimulating tissue repair. PBM has long been used as a means to increase circulation and improve tissue repair by enhancing new blood vessel formation through increases in vascular endothelial growth factor release and hypoxiainduced factor- $1 \alpha$ expression. ${ }^{25}$ PBM has been shown to improve the angiogenic impact of ADS by increasing its viability and encouraging the release of cytokines in the cutaneous flap, ${ }^{26}$ ischemic limbs ${ }^{27}$ and injured skin. ${ }^{28}$

More than 100 recognized factors are involved in the insufficient skin injury repair observed in people with $\mathrm{DM}^{29}{ }^{29}$ The therapeutic use of a combination of beneficial mediators and biomodulators appears to be of benefit in non-healing wounds; they are likely to show a synergistic effect and can improve the success of a cure for different wound simulations. In recent experiments, Bayat group have reported the capability of the combination of PBM and conditioned media (CM) from human bone marrow mesenchymal stem cells (hBM-MSCs) to stimulate repair of weakened wounds in a rat model of streptozotocin (STZ)-induced DM1. The outcomes of these experiments showed that PBM+CM prompted anti-inflammatory and angiogenic actions, and accelerated skin injury repair in a DM1 simulation of an MRSA-infected skin injury. ${ }^{30}$ The combination of CM and PBM revealed a synergistic influence. ${ }^{31}$ Here, we intend to assess the impact of PBM and ADS treatments, alone and in combination, on the maturation step of a repair course of ischemic, delayed healing, and infected wound simulations in rats with DM1. The combined application of PBM and ADS could advance the repairing course and assist with healing severe cases of DFUs in people with DM. 


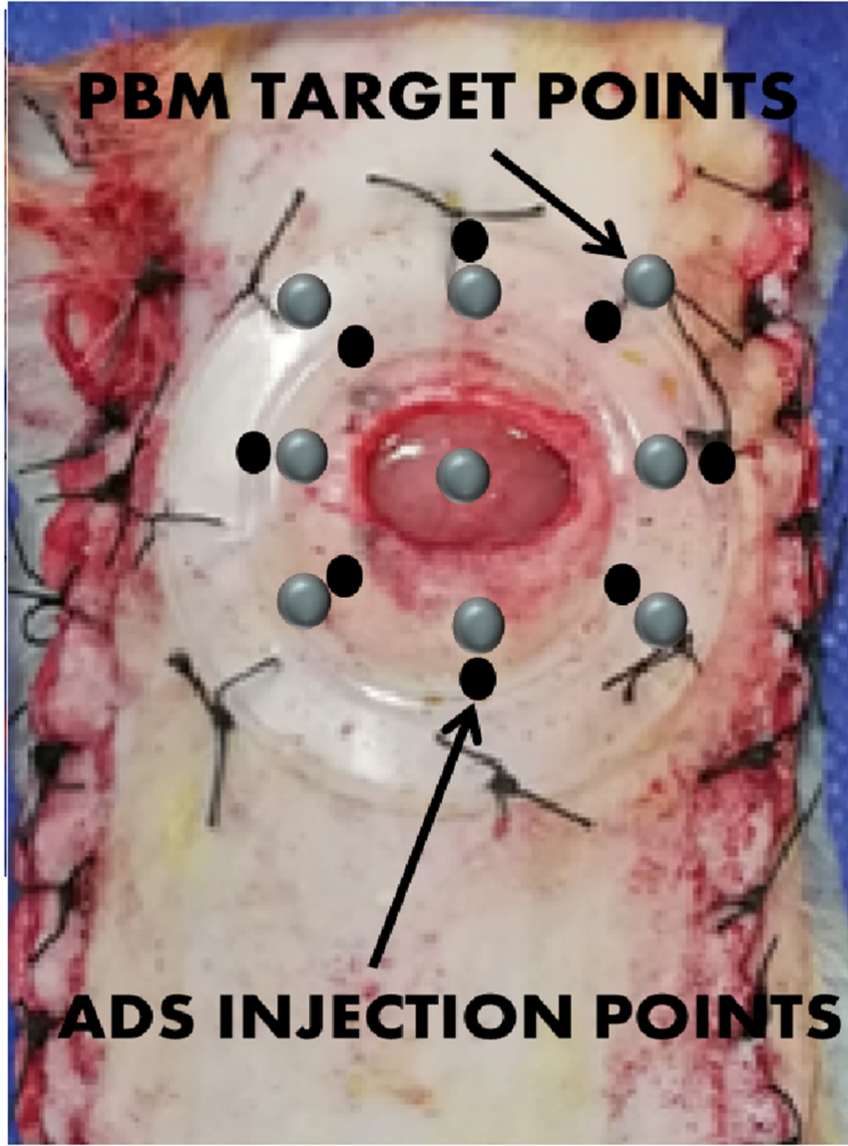

Figure 1 A photo of the wound, photobiomodulation (PBM) target points, and adipose-derived stem cells (ADS) injection points.

\section{MATERIALS AND METHODS}

\section{Animals and study design}

We randomly assigned 24 male Wistar rats aged 3 months into four groups ( $\mathrm{n}=6$ per group). Group 1 was the control (placebo) group. In group 2, allograft human ADS were transplanted. Group 3 received PBM treatment. The fourth group received an allograft of human ADS and PBM treatment. DM1 was induced in all rats. In addition, an ischemic, delayed healing and infected wound simulation was inflicted on all of the rats. We performed microbiological examinations, wound closure rate, wound strength and histological and stereological tests on days $0,4,8,12$ and 16 . We considered day 4 to be the inflammation step, day 8 to be the proliferation step and days 12 and 16 were the early and late maturation steps for the skin injury repair.

\section{Isolation, expansion and immunophenotyping of human hypodermis ADSs}

Human hypodermis adipose tissue was donated by a healthy adult donor (aged 35-40years) who underwent cosmetic mammoplasty surgery. The patient provided informed consent for the use of her tissue. Approximately 5 cc of adipose tissue was manually minced, washed with phosphate buffered saline (PBS) supplemented with $100 \mathrm{U} / \mathrm{mL}$ penicillin $+100 \mu \mathrm{g} / \mathrm{mL}$ streptomycin and subjected to digestion with $0.1 \%$ collagenase type I solution. Then, the cell pellets were suspended in Dulbecco's Modified Eagle's medium (DMEM) $+20 \%$ fetal bovine serum (FBS) and then seeded in T-75 flasks with DMEM+20\% FBS, and the above-mentioned antibiotics. We performed flow cytometry analysis to characterize the ADS cells for MSC markers, as reported previously. ${ }^{32} 33$

\section{ADS transplantation}

At 24 hours after surgery, we mixed $1 \times 10^{6}$ passage- 4 ADS cells $^{34}$ in $300 \mu \mathrm{L} \mathrm{PBS}{ }^{31}$ The mixture was immediately injected intradermally by an insulin syringe into eight sites around each wound at a $4-5 \mathrm{~mm}$ distance from the wound's margin (figure 1).

\section{Induction of DM1}

DM1 was induced through injection of STZ $(40 \mathrm{mg} / \mathrm{kg}$, intraperitoneal). ${ }^{31}$ DM1 was validated as a blood sugar level higher than $250 \mathrm{mg} / \mathrm{dL}$. All rats with diabetes were kept for 1 month to ensure that DM1 was established in the animals. ${ }^{31}$

\section{Clinical examinations}

We monitored the rats' body weights and blood sugar levels throughout the experiment.

\section{Surgery}

The rats were anesthetized by intramuscular injections of ketamine $(50 \mathrm{mg} / \mathrm{kg})$ and xylazine $(5 \mathrm{mg} / \mathrm{kg})$. A dorsal, bipedicle skin flap $(10 \times 3.5 \mathrm{~cm})$ was generated deep into the skin muscle. A $12 \mathrm{~mm}$ full-thickness excisional round wound that included the skin muscle was produced in the midpoint region of the flap by a biopsy punch. A donut-shaped silicone skin holder was fixed around each skin defect with a 04-silk suture (figure 1). Before surgery, all rats were treated with $20 \mathrm{mg} / \mathrm{kg}$ ibuprofen every 8-12 hours, which was continued until 5 days after surgery.

\section{Inoculation of MRSA into the wounds and microbiological examination}

We used the MRSA strain of S. aureus (ATCC 25923) according to a previously described procedure. ${ }^{31}$ In summary, a colony of MRSA was prepared for a final concentration of $2 \times 10^{8}$ at $1 \mathrm{cc}$ and a $100 \mu \mathrm{L}$ aliquot that contained $2 \times 10^{7}$ MRSA was administered topically onto each wound immediately after surgery. Microbiological samples for routine microbiological analyses were taken from the wounds on days 8 and 16. The numbers of bacterial per animal were counted as colony-forming units (CFUs). ${ }^{31}$

\section{Photobiomodulation}

Wounds from the rats in groups 3 and 4 were subjected to PBM immediately after surgery, which continued for 6 days per week for 16 days. The rats were sedated with the anesthetizing drugs (figure 1 ) ${ }^{31}$ Since the PBM target area (wound area and adjacent unwounded skin) was larger than laser probe beam area, we radiated nine 
Table 1 Complete specifications for the photobiomodulation

\begin{tabular}{ll}
\hline Parameters & Dose and unit \\
\hline Peak power output & $80 \mathrm{~W}$ \\
\hline Average power & $0.001 \mathrm{~W}$ \\
\hline Power density & $0.001 \mathrm{~W} / \mathrm{cm}^{2}$ \\
\hline Wavelength & $890 \mathrm{~nm}$ \\
\hline Wavelength range of the device & $890 \pm 10 \mathrm{~nm}$ \\
\hline Pulse frequency & $80 \mathrm{~Hz}$ \\
\hline Spot size & $1 \mathrm{~cm}^{2}$ \\
\hline Diameter & $1.12 \mathrm{~cm}$ \\
\hline Pulsed duration & $180 \mathrm{~ns}$ \\
\hline Duration of exposure for each point & $200 \mathrm{~s}$ \\
\hline Energy density & $0.2 \mathrm{~J} / \mathrm{cm}^{2}$ \\
\hline Number of laser shootings in each & 9 \\
session & \\
\hline Total energy densities at one session, & $1.8 \mathrm{and} \mathrm{25.2} \mathrm{J/}$ \\
and total sessions & $\mathrm{cm}^{2}$ \\
\hline Probe & L07 \\
\hline Company & MUSTANG 2000, \\
\hline
\end{tabular}

shootings of the laser probe in each session of PBM therapy in order to cover all target area $($ a $33 \mathrm{~mm} \times 33 \mathrm{~mm}$ quadrangular area including wound in the center and adjacent unwounded skin around wound), and to make sure that all the PBM target area could receive almost the same energy density of the PBM. Complete information of $\mathrm{PBM}$ protocol is reported in table 1 .

\section{Wound closure rate}

We photographed the wounds on days $0,4,8,12$ and 16 , and calculated and compared the wound closure rate in the study groups and at each time point.

Wound closure rate $=($ (original wound area-open area on $\mathrm{X}$ day)/original wound area $) \times 100 \% .^{35}$

\section{Wound strength examination}

We harvested one $5 \times 50 \mathrm{~mm}$ standard sample from the wounds of all the euthanized rats at day 16 after they were euthanized. The samples were placed in a material testing machine. The deformation ratio was 0.166 $\mathrm{mm} / \mathrm{s}$. From the load-deformation curve, we calculated the tensiometeric properties including bending stiffness $(\mathrm{MPa})$, maximum force $(\mathrm{N})$, stress high load $\left(\mathrm{N} / \mathrm{cm}^{2}\right)$ and energy absorption $(\mathrm{J})$ of the samples. ${ }^{31}$

\section{Histological and stereological analyses}

The sample from euthanized rats were excised, prepared for light histological study and serially sectioned into $5 \mu \mathrm{m}$ sections. We stained 10 sections by H\&E and 5 sections by Mallory's trichrome staining methods.

\section{Estimation of the cell numbers}

The physical dissector method was used to determine the numerical density $(\mathrm{Nv})$ of the neutrophils, macrophages, and fibroblasts, as follows:

$$
\mathrm{Nv}=\sum \mathrm{Q} /\left(\mathrm{h} \times \mathrm{a} / \mathrm{f} \times \sum \mathrm{p}\right)
$$

where $\mathrm{Nv}$ is numerical density; $\Sigma Q$ is number of nuclei; $\mathrm{h}$ is height of the dissector; $\mathrm{a} / \mathrm{f}$ is counting frame area; $\Sigma \mathrm{p}$ is number of counting frames in all fields.

$\mathrm{N}$ (total of cells in each rat) $=\mathrm{Nv} \times \mathrm{V}$

where $\mathrm{Nv}$ is numerical density; $\mathrm{V}$ is final total volume. ${ }^{35}$ Estimation of vascular length $=2 \Sigma Q /(\Sigma \mathrm{p} \times \mathrm{a} / \mathrm{f})$

where $2 \Sigma Q$ (total number of the vessel profiles counted per rat skin) $/ \Sigma \mathrm{P}$ (number of counting frames in all fields $(\mathrm{a} / \mathrm{f})) \cdot{ }^{36}$ Vascular length was considered as a biomarker for angiogenesis.

\section{Statistical analysis}

Data are shown as mean $\pm \mathrm{SD}$. We used the t-test, one-way analysis of variance, repeated measurement analysis and the least significant difference (LSD) tests for statistical analyses. A $p$ value of $<0.05$ was considered to be statistically significant.

\section{RESULTS}

\section{Marker expressions}

Flow cytometry analysis showed that the ADS cells slightly expressed CD $45(0.8 \%)$ and CD11b (0.33\%). In addition, the ADS cells completely expressed CD44H (100\%) and $\mathrm{CD} 105(100 \%)$ as seen in online supplementary material.

\section{Clinical observations}

All $\mathrm{p}$ values were related to the LSD test. All of the rats developed clinical evidence of DM1 with a significant increase in blood sugar levels and a decrease in body weight after STZ injection. On day 4, rats in the PBM and $\mathrm{PBM}+\mathrm{ADS}$ groups had a significant decrease in weight compared with the ADS group (LSD, $\mathrm{p}=0.006$ and 0.016 ) and the control group (LSD, $\mathrm{p}=0.020$ and 0.046 ), respectively. Although this downtrend continued for the PBM group until day 16, the PBM+ADS group experienced a weight gain. The combination of $\mathrm{PBM}+\mathrm{ADS}$ significantly increased body weight compared with PBM alone. Complete information of body weights and glucose levels are shown in table 2 , and by a graph in online supplementary material.

\section{Microbial findings \\ Day 8}

PBM+ADS treatment significantly decreased CFU in the wounds compared with ADS treatment $(\mathrm{p}=0.008)$ (figure 2).

\section{Day 16}

There were significant decreases in CFU in the PBM+ADS, $\mathrm{PBM}$ and ADS groups compared with the control group (all $\mathrm{p}=0.000$ ). Treatment with PBM+ADS was significantly 
Table 2 Comparison of body weights and blood sugar levels in the studied groups

\begin{tabular}{|c|c|c|c|c|}
\hline Groups $\rightarrow$ & & & & \\
\hline Factors $\downarrow$ & Control & PBM & ADS & PBM+ADS \\
\hline Initial blood sugar (mg/dL) & $445 \pm 44.96$ & $366.0 \pm 62.39$ & $332.86 \pm 72.89$ & $403.87 \pm 67.47$ \\
\hline Final blood sugar (mg/dL) & $460 \pm 21.03$ & $425.3 \pm 74.85^{\star \star}$ & $361.6 \pm 58.50$ & $354.14 \pm 60.93$ \\
\hline Initial body weight (g) & $310.4 \pm 12.6$ & $300.75 \pm 19.14$ & $301.57 \pm 12.2$ & $304.75 \pm 9.58$ \\
\hline Final body weight (g) & $265.75 \pm 15.95^{\star}$ & $246.5 \pm 14.26^{\star}$ & $295.80 \pm 14.17$ & $294 \pm 16.35$ \\
\hline
\end{tabular}

${ }^{*} \mathrm{P}<0.05,{ }^{* *} \mathrm{P}<0.01$; Student's t-test.

ADS, adipose-derived stem cell; PBM, photobiomodulation.

better than the individual PBM $(\mathrm{p}=0.006)$ and ADS $(p=0.003)$ treatments (figure 2$)$.

\section{Wound closure rate}

Day 4

There were no significant differences in the wound closure rate among the studied groups (figure 3).

Day 8

PBM+ADS $(p=0.000)$, PBM $(p=0.000)$ and ADS $(p=0.001)$ treatments significantly increased wound closure rate compared with the control group. Treatment with $\mathrm{PBM}+\mathrm{ADS}$ and $\mathrm{PBM}$ were significantly better than ADS treatment (both $\mathrm{p}=0.000$ ). At the same time, $\mathrm{PBM}+\mathrm{ADS}$ was significantly better than PBM treatment $(p=0.000)$ (figure 3).

\section{Day 12}

Treatment with PBM+ADS and PBM significantly increased wound closure rate compared with the control and ADS groups (all, $\mathrm{p}=0.000$ ) (figure 3 ).

\section{Day 16}

The PBM+ADSand PBM groups had significantly increased wound closure rate compared with the control and ADS groups (all, $\mathrm{p}=0.000$ ). $\mathrm{PBM}+\mathrm{ADS}$ treatment was significantly better than the individual PBM treatment $(\mathrm{p}=0.007)$ (figure 3).

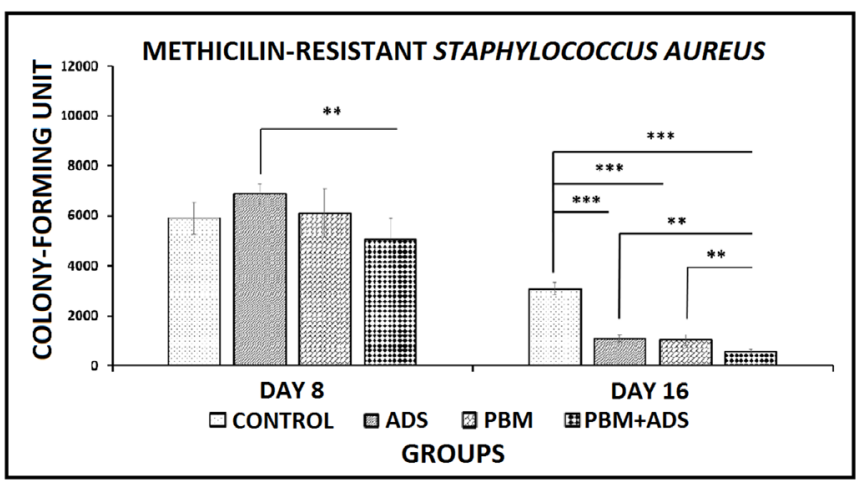

Figure 2 Comparison of colony-forming units (CFUs) of methicillin-resistant Staphylococcus aureus (MRSA) wounds in the groups by the least significant difference test. ${ }^{\star \star} \mathrm{P}<0.01 ;{ }^{\star \star \star} \mathrm{p}<0.001$. ADS, adipose-derived stem cell; $\mathrm{PBM}$, photobiomodulation.

\section{Wound strength, bending stiffness}

PBM+ADS $(p=0.000)$, PBM $(p=0.001)$ and ADS $(p=0.003)$ treatments significantly increased bending stiffness compared with the control group (figure 4A).

\section{Maximum force}

PBM+ADS $(\mathrm{p}=0.000), \operatorname{PBM}(\mathrm{p}=0.004)$ and ADS $(\mathrm{p}=0.035)$ treatments significantly increased maximum force compared with the control group. PBM+ADS treatment was significantly better than ADS treatment $(p=0.020)$ (figure 4B).

\section{Stress high load}

PBM+ADS $(\mathrm{p}=0.000), \operatorname{PBM}(\mathrm{p}=0.004)$ and ADS $(\mathrm{p}=0.035)$ treatments significantly increased stress high load compared with the control group. The PBM+ADS treatment was significantly better than the ADS treatment $(p=0.020)$ (figure 4C).

\section{Energy absorption}

All treatments significantly increased energy absorption compared with the control group (all, $\mathrm{p}=0.000$ ). Concurrently, ADS treatment was significantly better than treatment with PBM+ADS and PBM (both, $\mathrm{p}=0.000$ ) (figure 4D).

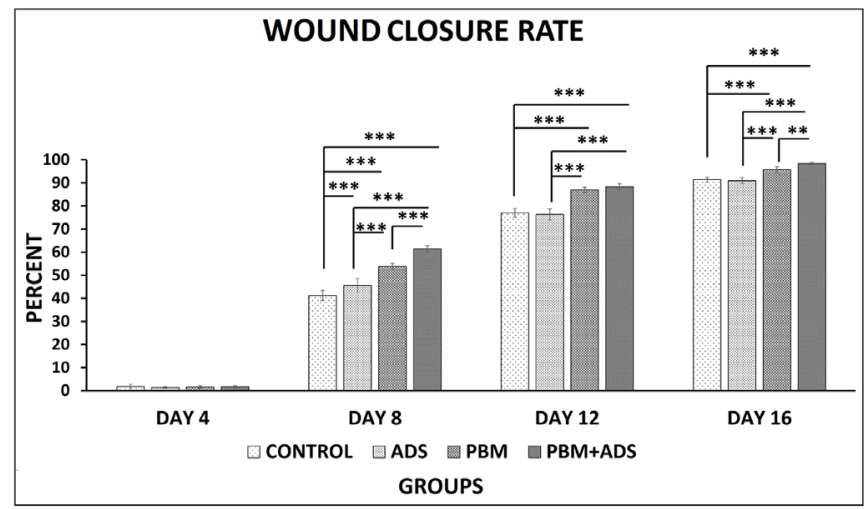

Figure 3 Comparison of wound closure rate from all of the groups by the least significant difference test. ${ }^{* \star} \mathrm{P}<0.01$; ${ }^{\star * *} \mathrm{p}<0.001$. ADS, adipose-derived stem cells; PBM, photobiomodulation. 


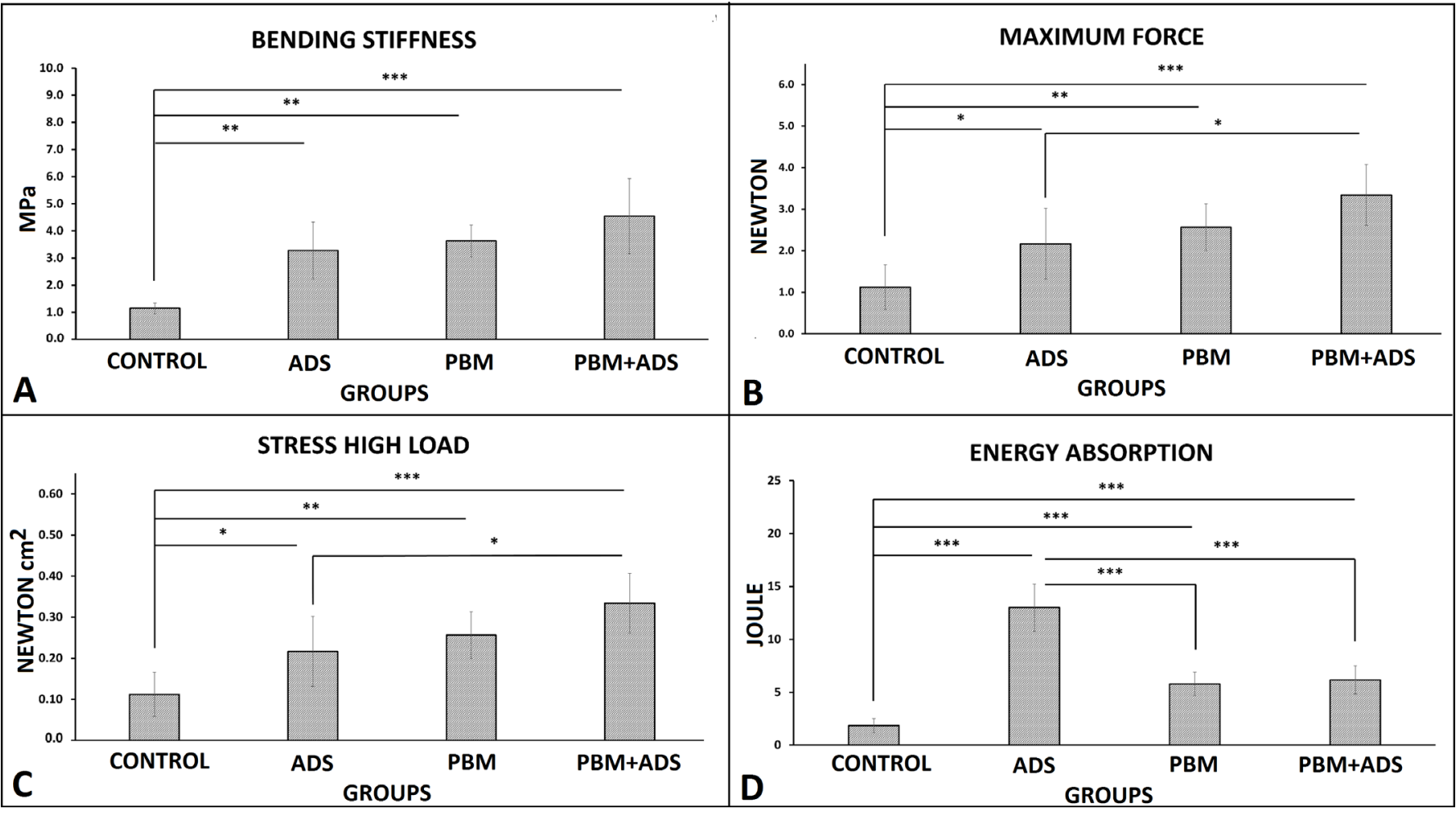

Figure 4 Comparison of bending stiffness (A), maximum force (B), stress high load (C), and energy absorption (D), of the wounds in the studied groups according to the least significant difference test. ${ }^{*} \mathrm{P}<0.05 ;{ }^{* *} \mathrm{p}<0.01$; ${ }^{* *} \mathrm{p}<0.001$. ADS, adiposederived stem cells; PBM, photobiomodulation.

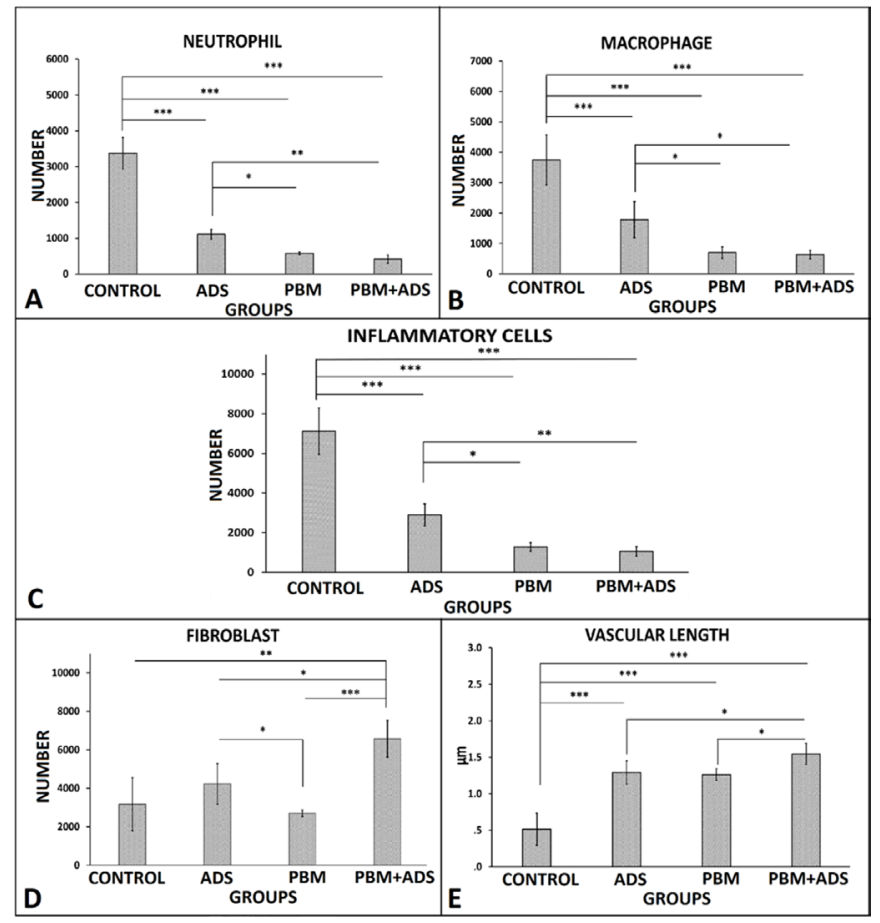

Figure 5 Comparison of number of neutrophil (A), macrophage (B), inflammatory cells (C), fibroblast (D) and vascular length (E) of wounds of four studied groups by LSD tests. ${ }^{*} \mathrm{P}<0.05 ;{ }^{* \star} \mathrm{p}<0.01 ;{ }^{* \star *} \mathrm{p}<0.001$. ADS, adipose-derived stem cells; PBM, photobiomodulation.

\section{Stereological findings}

In the cases of inflammatory cells (neutrophils and macrophages), all treatments regimes significantly decreased neutrophils and macrophages counts individually and totally (figure 5 , panels $\mathrm{A}, \mathrm{B}$ and $\mathrm{C}$, all $\mathrm{p}=0.000$ ). For neutrophil count, the results of $\mathrm{PBM}+\mathrm{ADS}$ and PBM were better than ADS $(p=0.001, p=0.01)$. For macrophage count, the results of PBM+ADS and PBM were better than ADS ( $p=0.017, p=0.032)$. For inflammatory cells count, the results of PBM+ADS and PBM were better than $\operatorname{ADS}(p=0.003, p=0.01)$. For fibroblast number, PBM+ADS significantly increased fibroblast number compared with $\mathrm{PBM}$, control and ADS groups $(\mathrm{p}=0.000, \mathrm{p}=0.012, \mathrm{p}=0.027)$ (figure 5, panel $\mathrm{D})$. ADS significantly increased fibroblast number compared with PBM $(\mathrm{p}=0.04)$. All treatments regimes significantly increased vascular length compared with control group. In case of angiogenesis, we observed significantly more vascular length in PBM+ADS compared with ADS and PBM ( $\mathrm{p}=0.007, \mathrm{p}=0.029$ ) (figure 5, panel E).

Histological micrographs of four studied groups which were stained with $\mathrm{H} \& \mathrm{E}$ staining method are shown in online supplementary materials.

\section{Findings of Mallory's trichrome staining}

Photos of Mallory's trichrome staining are shown in online supplementary materials. Collagen fibers orientation in control group were mixed, while in treatment 
groups were mostly horizontal. Pattern of collagen fibers in control group were mostly reticular and thin, whereas in treatment groups they were mostly fascicular and they seem thicker than collagen fibers of the control group.

\section{DISCUSSION}

In the current study, we evaluated the impact of PBM and ADS administration alone and together on the maturation step of the repair process in an ischemic, delayed healing and infected wound simulation in rats with DM1.

The complications in treatment of DFUs include an aberrant regional milieu, excessive inflammation and angiogenesis maladies. ${ }^{37}$ The results from this study indicated that all three treatment regimens significantly modulated inflammatory response, and significantly increased angiogenesis on day 16.

A previous study from one of the authors of the current study have shown that because of ADSs immunomodulatory impressions, they might be considered an appropriate treatment of some inflammatory diseases in healthy individuals and patients with DM. ${ }^{38}$ The most recent tissue engineering methods in stem cell therapy have shown encouraging choices to repair the weakened, injured skin, including DFUs. Stem cell therapy has arisen as a unique healing method for many illnesses, comprising injury repair and tissue restoration. Many diverse stem cell types have been considered in both animal and human studies and included BM-MSCs and ADS cells for wound repair. Fat tissue provides a plentiful source for MSCs and has shown promising results in wound repair experiments. ADS cells have the capability to change into different cell lines and release paracrine factors that start the tissue restoration process. The plentiful source of adipose tissue, simplicity of extraction, huge proliferative abilities in vitro and their capacity to release pro-angiogenic cytokines make them a perfect cell type as treatment for chronic wounds and wounds. ${ }^{39}$ In addition, ADS cells can be very valuable for medical use as they prevent immunological reactions and do not require a chief histocompatibility equivalent for allogeneic engraftment. ${ }^{40}$ Engraftment of ADSs encourages new blood vessel formation and increases blood flow to the ischemic organ in mice. ${ }^{41}$ It has also been revealed that growth factors released by ADS cells stimulate arteriogenesis in ischemic tissue by paracrine signaling. ${ }^{41} 42$

To our knowledge, the combination of PBM+ADS on the repair of infected wounds in patients or animals with DM1 has not been documented. This study aimed to assess the impacts of PBM+ADS on microbial flora, wound area, wound strength and histological parameters in rats with DM1. We found that the use of PBM or ADS alone, or together significantly increased skin injury repair of the MRSA-infected wounds in rats with DM1. Additionally, PBM+ADS showed a synergistic impact. Therefore, PBM+ADS treatment was significantly better than individual treatment by PBM or ADS. This was probably the result of the enhanced survival of ADSs by inhibition of apoptosis, along with increased paracrine signaling of ADS under the influence of PBM. ${ }^{27} 28$

Our data demonstrated that an anti-inflammatory agent as well as a mitogenic agent, PBM, displayed a synergistic impression on ADS-prompted skin injury repair in rats (figure 5). The wound closure rate was increased in the group that received PBM+ADS. Interestingly, the initiation of bactericidal impact by ADSs was specially improved by PBM, companioned by the elevated wound strength. These outcomes suggested that administration of PBM at the right protocol might assist with the healing effects of ADS in a DM1 simulation of an MRSA-infected ischemic delayed healing wound. Taken together, our findings recommend that PBM, an anti-inflammatory and mitogen agent, along with a cost-effective modality could be a beneficial enhancement for ADS-based therapy in treating DFUs.

Guo and DiPietro in their review article emphasized on important of wound strength in different medical situations. ${ }^{43}$ Our study showed that treatment of wounds with ADS significantly increased wound strength compared with control and PBM groups. This result showed importance of ADS in treating non healing wounds such as diabetic wounds. However, combined administration of ADS and PBM demonstrated a synergistic effect. In current study, the results of fibroblast count and Mallory's trichrome stain were in the line of wound strength results.

In the current study, stereological analysis supported our hypothesis that the treatments, particularly PBM+ADS modulated the inflammatory response, simultaneously increased wound strength and wound closure rate, and significantly decreased the CFU.

It should also be noted that our unique outcomes reveal the synergistic impact of PBM+ADS on skin injury repair in comparison with other related experiments that only investigated the impression of a solo cure with either $\mathrm{PBM}^{44}$ or ADS. ${ }^{18}$

Bacterial contamination is a main contributing issue in the deterioration of wound healing. ${ }^{45}$ MRSA is a common staphylococcal strain accountable for numerous regional and general contaminations that quickly progresses to resistance to regularly recommended antibiotics. Therefore, the observed occurrence and adaptation of MRSA in DFUs ${ }^{9}$ has stemmed from a growing range of non-curable staphylococcal contaminations. ${ }^{46}$ Novel approaches to treat MRSA contamination and counter the growing complication of MRSA are mandatory. ${ }^{34}$ Specifically, our experiment aimed to focus on the bactericidal effects of $\mathrm{PBM}^{47}$ and $\mathrm{ADS}^{34}$ because both have been individually reported to have bactericidal effects in animal models. To date, there is no probe that has examined the effects of PBM on immunomodulation of ADS.

Our outcomes (figure 2) show that PBM treatment could further promote the immunomodulatory efficacy of ADS and might be medically applicable to cell therapies, while better healing impact are required as DFUs, or scalds. In a study of a culture system probe with PBM $\left(415 \mathrm{~nm}, 100 \mathrm{~mW}\right.$ and $\left.30,60,120 \mathrm{~J} / \mathrm{cm}^{2}\right)$, Lipoveski et al presented an inhibitory impact on $S$. aureus growth 
by stimulation of ROS synthesis. ${ }^{48}$ Consistent with this finding, we hypothesized that the bactericidal effect of the PBM-treated groups in this probe might be due to the induction of ROS by PBM.

Several studies have suggested that stem cells, specifically ADS cells, can speed up repair of a wound, and ADS cells can employ many actions to stimulate skin injury repair. In theory, ADS cells might immediately contribute to tissue restoration by renewing impaired cells via epidermal differentiation, ${ }^{49}$ although the weak efficiency of ADS transplantation and viability at the injury site has restricted this direct involvement. ${ }^{20-23}$ Recent investigations have shown significant decreases in stem cells quantity in some experimental simulations of fractures and wounds within the first 14 days of engraftment. Wu et al reported a considerable increase in stem cell survival 7 days after creating the skin injury and a fast decrease in surviving cells 14 days after the infliction of this skin injury. ${ }^{50}$ Levi et al studied the effect of human ADS implantation on the repair of a non-healing mice skull defect. They observed significant repair in the implanted skull defect. In their study, at 28 and 56 days after the human ADS implantation, many of the fluorescence in situ hybridization positive cells were not recognized. ${ }^{51}$ The outcomes from two probes demonstrated that some implanted ADS cells expressed endothelial markers and were absorbed into vascular networks in ischemic organs, but the rate of contribution was small because many cells expired inside the hypoxic milieu of the ischemic organ. ${ }^{52}$ Hence, to improve positive stem cell therapies, it is essential to improve stem cell function, so they can stay alive in ischemic tissue and be able to differentiate into vascular cells, as well. ${ }^{53}$

PBM has been successfully applied for enhancement of local blood circulation and improve repair of an injury by triggering new blood vessel formation in some non-diabetic animal simulations of ischemic tissues. ${ }^{25}$ Park et al reported that the release of cytokines was greater in the ADS+PBM group compared with the ADS-only group in a random skin flap (RSF) in mice. ADS improved tissue repair by endothelial cell differentiation and release of angiogenic growth factors. The ADS+PBM group showed better treatment efficiency in comparison with ADS alone. Park et al found that transplanting ADSs to ischemic RSF enhanced healing efficiency for ischemia as an outcome of improved $\mathrm{ADS}$ viability and paracrine impact. Moreover, Park et al concluded that PBM improved the viability of ADS and encouraged the release of growth factors in RSF. ${ }^{27}$

The impacts of PBM+CM of hBM-MSC on the infected wounds in rats with diabetes were studied by Bayat group. In the first study, Kouhkheil et al reported the positive impacts of PBM $\left(890 \mathrm{~nm}, 80 \mathrm{~Hz}, 0.2 \mathrm{~J} / \mathrm{cm}^{2}\right)$ and $\mathrm{CM}$ from hBM-MSCs (four injections) together and alone on the $\mathrm{CFU}$ and wound strength of an infected wound simulation with MRSA in rats with DM1. ${ }^{31}$ In the second study, Fridoni et al demonstrated the positive impact of PBM $\left(890 \mathrm{~nm}, 80 \mathrm{~Hz}, 0.2 \mathrm{~J} / \mathrm{cm}^{2}\right)$ and $\mathrm{CM}$ from hBM-MSC (four injections) alone or together on the stereological parameters of an infected wound simulation with MRSA in rats with DM1. Fridoni et al determined that the use of $\mathrm{PBM}+\mathrm{CM}$ prompted anti-inflammatory and neovascular actions, and hastened skin injury repair in an MRSAinfected injury in rats with DM1. ${ }^{30}$

In current study, stereological analysis supports our hypothesis regarding our treatments and especially PBM+ADS modulates inflammatory response and at the same time increases wound strength, and significantly increased wound closure rate and CFU. Bayat and Chien have reported the positive effects of combined application of ADS and PBM in some ischemic tissues. They stressed that these results might support new healing attitudes for a cure and resolution of delayed healing of DFU in patients. ${ }^{54}$

\section{CONCLUSION}

PBM and ADS alone or together significantly hasten the skin injury repair in an ischemic delayed healing and MRSA-infected wound simulation in rats with DM1. Furthermore, combined use of PBM and ADS have confirmed a synergistic impact. We suggest that PBM+ADS treatment should be used for infected skin injuries and wounds in translational studies, and in patients to reduce inflammation, and infection, and promote repair. Additional details of cellular and molecular mechanisms regarding the effect of $\mathrm{PBM}+\mathrm{ADS}$ on the repair of ischemic delayed healing and MRSA-infected wounds in rats with DM1 should be elucidated by further research.

\section{Author affiliations}

${ }^{1}$ Department of Biology and Anatomical Sciences, School of Medicine, Shahid Beheshti University of Medical Sciences, Tehran, Iran

${ }^{2}$ Department of Anatomy, Faculty of Medicine, Tehran Medical Sciences, Islamic Azad University, Tehran, Iran

${ }^{3}$ Department of Immunology, School of Medicine, Shahid Beheshti University of Medical Sciences, Tehran, Iran

${ }^{4}$ Urogenital Stem Cell Research Center, Shahid Beheshti University of Medical Sciences, Tehran, Iran

${ }^{5}$ Department of Microbiology, School of Medicine, Shahid Beheshti University of Medical Sciences, Tehran, Iran

${ }^{6}$ Department of Statistics, University of Qom, Qom, Iran

${ }^{7}$ Price Institute of Surgical Research, University of Louisville, and Noveratech LLC of Louisville, Louisville, Kentucky, USA

${ }^{8}$ Department of Medicine, Division of Hematology/Oncology, Department of Immunology and Microbiology, Cancer Center, Rush University Medical Center, Chicago, Illinois, USA

${ }^{9}$ Illinois Institute of Technology, Chicago, Illinois, USA

Correction notice This article has been corrected since it was published. Dr. Abdollah Amini is added as co-corresponding author.

Contributors $\mathrm{MB}$ is the guarantor of this work, and researched data and wrote the manuscript. SC, AA, and SMH contributed to the conception and design. RE-M, FZ, AM, SD, ND, MR, MH, and HA performed the experiments and collection of data and SB primary edited the manuscript. SKG contributed to the data analysis and interpretation. SC and SS edited scientifically the manuscript.

Funding This study was financially supported by the Research Department of the School of Medicine at Shahid Beheshti University of Medical Sciences (grant no. 14601). SC was supported in part by NIH grant DK105692.

Competing interests None declared.

Patient consent for publication Not required.

Ethics approval The IACUC of the School of Medicine at Shahid Beheshti University of Medical Sciences (SBMU) approved this experiment (file no: IR.SBMU.MSP. REC.1398.394). 
Provenance and peer review Not commissioned; externally peer reviewed.

Data availability statement Data are available upon reasonable request.

Open access This is an open access article distributed in accordance with the Creative Commons Attribution Non Commercial (CC BY-NC 4.0) license, which permits others to distribute, remix, adapt, build upon this work non-commercially, and license their derivative works on different terms, provided the original work is properly cited, appropriate credit is given, any changes made indicated, and the use is non-commercial. See: http://creativecommons.org/licenses/by-nc/4.0/.

ORCID iD

Mohammad Bayat http://orcid.org/0000-0001-5214-4223

\section{REFERENCES}

1 American Diabetes Association. Diagnosis and classification of diabetes mellitus. Diabetes Care 2004;27 Suppl 1:S5-10.

2 Cho NH, Shaw JE, Karuranga S, et al. IDF diabetes atlas: global estimates of diabetes prevalence for 2017 and projections for 2045. Diabetes Res Clin Pract 2018;138:271-81.

3 Clayton W, Elasy TA. A review of the pathophysiology, classification, and treatment of foot ulcers in diabetic patients. Clinical Diabetes 2009;27:52-8.

4 Lepäntalo M, Apelqvist J, Setacci C, et al. Chapter V: diabetic foot. Eur J Vasc Endovasc Surg 2011;42 Suppl 2:S60-74.

5 Giacco F, Brownlee M. Oxidative stress and diabetic complications. Circ Res 2010;107:1058-70.

6 Alexiadou K, Doupis J. Management of diabetic foot ulcers. Diabetes Therapy 2012;3:4.

7 Raghav A, Khan ZA, Labala RK, et al. Financial burden of diabetic foot ulcers to world: a progressive topic to discuss always. Ther Adv Endocrinol Metab 2018;9:29-31.

8 Rice JB, Desai U, Cummings AKG, et al. Burden of diabetic foot ulcers for Medicare and private insurers. Diabetes Care 2014;37:651-8.

9 Boulton AJ, Armstrong DG, Kirsner RS, et al. Diagnosis and management of diabetic foot complications, 2018. Available: https:// www.ncbi.nlm.nih.gov

10 Eleftheriadou I, Tentolouris N, Argiana V, et al. MethicillinResistant Staphylococcus aureus in diabetic foot infections. Drugs 2010;70:1785-97.

11 Lipsky BA. Diabetic foot infections: Current treatment and delaying the 'post-antibiotic era'. Diabetes Metab Res Rev 2016;32:246-53.

12 Catrina S-B, Zheng X. Disturbed hypoxic responses as a pathogenic mechanism of diabetic foot ulcers. Diabetes Metab Res Rev 2016;32:179-85

13 Wood S, Jayaraman V, Huelsmann EJ, et al. Pro-Inflammatory chemokine CCL2 (MCP-1) promotes healing in diabetic wounds by restoring the macrophage response. PLoS One 2014;9:e91574.

14 Landén NX, Li D, Ståhle M. Transition from inflammation to proliferation: a critical step during wound healing. Cell Mol Life Sci 2016;73:3861-85.

15 Powers JG, Higham C, Broussard K, et al. Wound healing and treating wounds: chronic wound care and management. J Am Acad Dermatol 2016;74:607-25.

$16 \mathrm{Hu}$ MS, Borrelli MR, Lorenz HP, et al. Mesenchymal stromal cells and cutaneous wound healing: a comprehensive review of the background, role, and therapeutic potential. Stem Cells Int 2018;2018:6901983.

17 Gadelkarim M, Abushouk Al, Ghanem E, et al. Adipose-Derived stem cells: effectiveness and advances in delivery in diabetic wound healing. Biomed Pharmacother 2018;107:625-33.

18 Irons RF, Cahill KW, Rattigan DA, et al. Acceleration of diabetic wound healing with adipose-derived stem cells, endothelialdifferentiated stem cells, and topical conditioned medium therapy in a swine model. J Vasc Surg. In Press 2018;68:115S-25.

19 Lopes L, Setia O, Aurshina A, et al. Stem cell therapy for diabetic foot ulcers: a review of preclinical and clinical research. Stem Cell Res Ther 2018;9:188.

20 Yao YZ, Deng CL, Wang B. [Advances in the research of influence of diabetes in biological function of adipose-derived stem cells]. Zhonghua Shao Shang Za Zhi 2018;34:653-6.

$21 \mathrm{Kim}$ SM, Kim YH, Jun YJ, et al. The effect of diabetes on the wound healing potential of adipose-tissue derived stem cells. Int Wound $J$ 2016;13:33-41.

22 Cronk SM, Kelly-Goss MR, Ray HC, et al. Adipose-Derived stem cells from diabetic mice show impaired vascular stabilization in a murine model of diabetic retinopathy. Stem Cells Trans/ Med 2015;4:459-67.

23 Rennert RC, Sorkin M, Januszyk M, et al. Diabetes impairs the angiogenic potential of adipose-derived stem cells by selectively depleting cellular subpopulations. Stem Cell Res Ther 2014;5:79.
24 Farivar S, Malekshahabi T, Shiari R. Biological effects of low level laser therapy. J Lasers Med Sci 2014;5:58-62.

25 Cury V, Moretti AIS, Assis L, et al. Low level laser therapy increases angiogenesis in a model of ischemic skin flap in rats mediated by VEGF, HIF- $1 \alpha$ and MMP-2. Journal of Photochemistry and Photobiology B: Biology 2013;125:164-70.

26 Park I-S, Mondal A, Chung P-S, et al. Vascular regeneration effect of adipose-derived stem cells with light-emitting diode phototherapy in ischemic tissue. Lasers Med Sci 2015;30:533-41.

27 Park I-S, Mondal A, Chung P-S, et al. Prevention of skin flap necrosis by use of adipose-derived stromal cells with light-emitting diode phototherapy. Cytotherapy 2015;17:283-92.

$28 \mathrm{Kim} \mathrm{H}$, Choi K, Kweon O-K, et al. Enhanced wound healing effect of canine adipose-derived mesenchymal stem cells with low-level laser therapy in athymic mice. J Dermatol Sci 2012;68:149-56.

29 Brem H, Tomic-Canic M. Cellular and molecular basis of wound healing in diabetes. J Clin Invest 2007:117:1219-22.

30 Fridoni M, Kouhkheil R, Abdollhifar Mohammad-Amin, et al. Improvement in infected wound healing in type 1 diabetic rat by the synergistic effect of photobiomodulation therapy and conditioned medium. J Cell Biochem 2019;120:9906-16.

31 Kouhkheil R, Fridoni M, Piryaei A, et al. The effect of combined pulsed wave low-level laser therapy and mesenchymal stem cell-conditioned medium on the healing of an infected wound with methicillin-resistant Staphylococcal aureus in diabetic rats. J Cell Biochem 2018;119:5788-97.

32 Zhu Y, Liu T, Song K, et al. Adipose-Derived stem cell: a better stem cell than BMSC. Cell Biochem Funct 2008;26:664-75.

33 Muhammad G, Xu J, Bulte JWM, et al. Transplanted adiposederived stem cells can be short-lived yet accelerate healing of acid-burn skin wounds: a multimodal imaging study. Sci Rep 2017;7:4644.

34 Mot YY, Othman I, Sharifah SH. Synergistic antibacterial effect of co-administering adipose-derived mesenchymal stromal cells and Ophiophagus hannah L-amino acid oxidase in a mouse model of methicillin-resistant Staphylococcus aureus-infected wounds. Stem Cell Res Ther 2017;8:5.

35 Yuan Z, Zhao J, Chen Y, et al. Regulating inflammation using acidresponsive electrospun fibrous scaffolds for skin scarless healing. Mediators Inflamm 2014;2014:1-11.

36 Babaei S, Bayat M, Nouruzian M, et al. Pentoxifylline improves cutaneous wound healing in streptozotocin-induced diabetic rats. Eur J Pharmacol 2013;700:165-72.

$37 \mathrm{Lu} \mathrm{H}$, Wu X, Wang Z, et al. Erythropoietin-activated mesenchymal stem cells promote healing ulcers by improving microenvironment. $J$ Surg Res 2016;205:464-73.

38 Rahavi H, Hashemi SM, Soleimani M, et al. Adipose tissue-derived mesenchymal stem cells exert in vitro immunomodulatory and beta cell protective functions in streptozotocin-induced diabetic mice model. J Diabetes Res 2015;2015:1-10.

39 Hassan WU, Greiser U, Wang W. Role of adipose-derived stem cells in wound healing. Wound Repair Regen 2014;22:313-25.

40 González MA, Gonzalez-Rey E, Rico L, et al. Adipose-Derived mesenchymal stem cells alleviate experimental colitis by inhibiting inflammatory and autoimmune responses. Gastroenterology 2009;136:978-89.

41 Harada Y, Yamamoto Y, Tsujimoto S, et al. Transplantation of freshly isolated adipose tissue-derived regenerative cells enhances angiogenesis in a murine model of hind limb ischemia. Biomed Res 2013;34:23-9.

42 Sumi M, Sata M, Toya N, et al. Transplantation of adipose stromal cells, but not mature adipocytes, augments ischemia-induced angiogenesis. Life Sci 2007;80:559-65.

43 Guo S, DiPietro LA. Factors affecting wound healing. J Dent Res 2010;89:219-29.

44 Sharifian Z, Bayat M, Alidoust M, et al. Histological and gene expression analysis of the effects of pulsed low-level laser therapy on wound healing of streptozotocin-induced diabetic rats. Lasers Med Sci 2014;29:1227-35.

45 Edwards R, Harding KG. Bacteria and wound healing. Curr Opin Infect Dis 2004;17:91-6.

46 Smith TL, Pearson ML, Wilcox KR, et al. Emergence of Vancomycin Resistance in Staphylococcus aureus. N Engl J Med Overseas Ed 1999;340:493-501.

47 Ranjbar R, Takhtfooladi MA. The effects of low level laser therapy on Staphylococcus aureus infected third-degree burns in diabetic rats. Acta Cirurgica Brasileira 2016;31:250-5.

48 Lipovsky A, Nitzan Y, Gedanken A, et al. Visible light-induced killing of bacteria as a function of wavelength: implication for wound healing. Lasers Surg Med 2010;42:467-72. 
$49 \mathrm{Li}$ P, Guo X. A review: therapeutic potential of adipose-derived stem cells in cutaneous wound healing and regeneration. Stem Cell Res Ther 2018;9:302.

50 Wu Y, Chen L, Scott PG, et al. Mesenchymal stem cells enhance wound healing through differentiation and angiogenesis. Stem Cells 2007;25:2648-59.

51 Levi B, James AW, Nelson ER, et al. Human adipose derived stromal cells heal critical size mouse calvarial defects. PLoS One 2010;5:e11177.

52 Nakagami H, Maeda K, Morishita R, et al. Novel autologous cell therapy in ischemic limb disease through growth factor secretion by cultured adipose tissue-derived stromal cells. Arterioscler Thromb Vasc Biol 2005;25:2542-7.

53 Bhang SH, Cho S-W, La W-G, et al. Angiogenesis in ischemic tissue produced by spheroid grafting of human adipose-derived stromal cells. Biomaterials 2011;32:2734-47.

54 Bayat M, Chien S. Combined adipose-derived mesenchymal stem cells and Photobiomodulation could modulate the inflammatory response and treat infected diabetic foot ulcers. Photobiomodulation, Photomedicine, and Laser Surgery 2019. 